\title{
MATERNAL ANTENATAL PROFILE IN VLBW AND ELBW BABIES
}

\author{
Pranoy Dey¹, Farzana Zahir², Ram Krishna Jha ${ }^{3}$, Rajeev Ranjan ${ }^{4}$
}

${ }^{1}$ Associate Professor, Department of Paediatrics, Assam Medical College, Dibrugarh, Assam, India.

${ }^{2}$ Assistant Professor, Department of Obstetrics and Gynaecology, Assam Medical College, Dibrugarh, Assam, India.

3 Postgraduate Trainee, Department of Paediatrics, Assam Medical College, Dibrugarh, Assam, India.

4 Postgraduate Trainee, Department of Paediatrics, Assam Medical College, Dibrugarh, Assam, India.

\begin{abstract}
BACKGROUND

Very Low Birth Weight (VLBW) and Extreme Low Birth Weight (ELBW) babies are always a challenge for a neonatologist in relation to good neurodevelopmental outcome. Preterm birth is one of the major clinical problems in obstetrics and neonatology as it is associated with perinatal mortality, serious neonatal morbidity, and in some cases childhood disability. It is reported that 60$80 \%$ of all neonatal mortality and morbidity is due to preterm birth. During the last two decades, the survival for premature infants has significantly increased due to advancement in perinatal and neonatal treatment expertise and improvement in the care of highrisk mother. The survival rate of low birth weight baby is reported to have increased from $10 \%$ to $60 \%$. The survivors of preterm birth especially when born at $<34$ weeks of gestation should remain in newborn intensive care unit (NICU). They need to spend time in NICU till close to term to allow for sufficient multi-organ maturation resulting in prolonged hospital stay for both mother and infant. Therefore, the consequences of preterm birth often continue beyond the neonatal period and can lead to significant direct and indirect costs that have to be borne by parents and society. Hence, a better understanding of maternal antenatal factors contributing to preterm birth and need for improvement of antenatal and perinatal care are necessary to increase the neonatal survival. This retrospective study of maternal antenatal profile of very low birth weight ( $<1500$ gm) and extremely low birth weight $(<1000 \mathrm{gm})$ babies is very important so that adequate attention can be given to overcome these medical consequences.
\end{abstract}

\section{METHODS}

This retrospective descriptive study was conducted in the department of Obstetrics and Gynaecology, A.M.C.H. Dibrugarh, Assam, for a period of $01 / 12 / 2017$ to $30 / 11 / 2018$.

\section{RESULTS}

A total number of 72 mothers who delivered VLBW and ELBW babies was included in this study. The maternal and antenatal profiles associated with the delivery of VLBW and ELBW babies were studied, which shows that anaemia ( 32 cases- $38.09 \%$ ) is the most common cause of delivery of VLBW and ELBW babies, followed by PIH associated in 25 cases (29.76\%) then multiple pregnancy in 12 cases (14.28\%) and idiopathic causes in 11 cases in which no predisposing factors were identified probably because some of the cases are unbooked. In 4 cases (4.76\%), UTI with pyelonephritis was found to be associated with delivery of VLBW and ELBW babies.

\section{CONCLUSIONS}

VLBW \& ELBW babies are always a challenge for a neonatologist with regard to good neurodevelopmental outcome. We found that anaemia, pregnancy induced hypertension, twin pregnancy, and UTI with pyelonephritis were common associations with preterm delivery. Some of these risk factors may be remediable if adequate antenatal care is provided, and timely medical intervention is done.

HOW TO CITE THIS ARTICLE: Dey P, Zahir F, Jha RK, et al. Maternal antenatal profile in VLBW and ELBW babies. J. Evolution Med. Dent. Sci. 2019;8(15):1237-1239, DOI: 10.14260/jemds/2019/274

\section{BACKGROUND}

Very Low Birth Weight (VLBW) and Extreme Low Birth Weight (ELBW) babies are always a challenge for a neonatologist with regard to good neurodevelopmental outcome. Preterm birth is one of the major clinical problems in obstetrics and neonatology as it is associated with perinatal mortality, serious neonatal morbidity and in some cases childhood disability.

'Financial or Other Competing Interest': None.

Submission 19-02-2019, Peer Review 29-03-2019,

Acceptance 05-04-2019, Published 15-04-2019.

Corresponding Author:

Dr. Farzana Zahir,

Assistant Professor,

Department of Obstetrics and Gynaecology,

Assam Medical College,

Dibrugarh, Assam, India.

E-mail: sajeedfarah@hotmail.com

DOI: $10.14260 /$ jemds $/ 2019 / 274$
It is reported that $60-80 \%$ of all neonatal mortality and morbidity is due to preterm birth. During the last two decades the survival for premature infants has significantly increased due to advancement in perinatal and neonatal treatment expertise and improvement in the care of high-risk mother. The survival rate of low birth weight baby is reported to have increased from $10 \%$ to $60 \%$. The survivors of preterm birth especially when born at $<34$ weeks of gestation require to remain in newborn intensive care unit (NICU). They need to spend time in NICU till close to term to allow for sufficient multi-organ maturation resulting in prolonged hospital stay for both mother and infant. Therefore, the consequence of preterm birth often continue beyond the neonatal period and can lead to significant direct and indirect costs that have to be borne by parents and society. Hence, a better understanding of maternal antenatal factors contributing to preterm birth and need for improvement of antenatal and perinatal care are necessary to increase the neonatal survival. 
Here this retrospective descriptive study of maternal antenatal profile of very low birth weight $(<1500 \mathrm{gm})$ and extremely low birth weight $(<1000 \mathrm{gm})$ babies is very important so that adequate attention can be given to overcome these medical consequences.

\section{METHODS}

This retrospective descriptive study was conducted in our department of Obstetrics and Gynaecology, A.M.C.H. for a period of $01 / 12 / 2017$ to $30 / 11 / 2018$ after obtaining approval from institutional ethics committee. This centre is the apex tertiary centre, caters to mainly high-risk pregnant mothers and equipped to handle any complication of labour, preterm labour from 26 weeks to 34 weeks period of gestation, was followed up till delivery. The detailed case record of the mother was entered, and it was reviewed. The maternal details like demographic profile, anaemia, bacterial vaginosis, gestational hypertension, previous history of preterm delivery, urinary tract infection, Rh isoimmunization, multiple pregnancy, heart disease, congenital malformation of uterus, first trimester bleeding, medical complications during pregnancy, antepartum haemorrhage, definite cause of preterm labour if any, treatment profile, intranatal care and delivery outcome was collected.

\section{Inclusion Criteria}

include pregnant women who have 2 or less than 2 antenatal check-ups till 26 weeks of gestation in AMCH, or not a booked case in AMCH deliver ELBW and VLBW baby in 26 to 34 weeks of gestation at $\mathrm{AMCH}$.

\section{Exclusion Criteria}

Delivery of ELBW and VLBW baby $<26$ weeks \& $>34$ weeks \& those delivered outside.

\section{RESULTS}

A total no of 72 mothers who delivered VLBW and ELBW babies were included in this study. Delivered 59 Patients were booked, and 13 patients were unbooked, so majority of patients were booked, in our study out of 72 patients, 48 were primigravida and 24 were multigravida.

The age of patients ranged from 18 years to 40 years.

There were 60 singleton pregnancies and 12 pairs of twin pregnancies giving a total of 84 babies.

\begin{tabular}{|c|c|c|}
\hline Birth Weight (gm) & Number of Babies Delivered & \% \\
\hline$<800$ & 6 & 7.14 \\
\hline $800-1000$ & 9 & 10.71 \\
\hline $1001-1250$ & 21 & 25 \\
\hline $1251-1500$ & 48 & 57.14 \\
\hline \multicolumn{2}{|c|}{ Table 1. Distribution of Babies Delivered on The Basis of } \\
Birth Weight \\
\hline
\end{tabular}

\begin{tabular}{|c|c|c|}
\hline Gestation Period & No. of Babies Delivered & $\mathbf{\%}$ \\
\hline$<28$ wks. & 6 & 7.14 \\
\hline $29-30$ wks. & 10 & 11.90 \\
\hline $31-32$ wks. & 21 & 25 \\
\hline 33-34 wks. & 47 & 55.95 \\
\hline Table 2. Distribution of Babies Delivered on The Basis of \\
Gestational Period \\
\hline
\end{tabular}

Among various maternal risk factors anaemia during pregnancy 10 , gestational hypertensions 15 , twin pregnancy
10 and. followed by UTI with pyelonephritis 4, rest are idiopathic 11 .

\begin{tabular}{|c|c|c|}
\hline Risk Factors & No. of Patients & \% of Patients \\
\hline Anaemia & 32 & 38.09 \\
\hline PIH & 25 & 29.76 \\
\hline Twin Pregnancy & 12 & 14.28 \\
\hline UTI & 4 & 4.76 \\
\hline Idiopathic & 11 & 13.09 \\
\hline Table 3. Maternal Risk Factors in VLBW and ELBW Babies \\
Delivered \\
\hline
\end{tabular}

\begin{tabular}{|c|c|c|}
\hline Anaemia & 26 & $36.11 \%$ \\
\hline PIH & 22 & $30.55 \%$ \\
\hline Twin Pregnancy & 9 & $12.5 \%$ \\
\hline UTI & 4 & $5.55 \%$ \\
\hline Idiopathic & 11 & $15.27 \%$ \\
\hline \multicolumn{2}{|c|}{ Table 4. Maternal Risk Factors in VLBW Babies Delivered } \\
\hline
\end{tabular}

\begin{tabular}{|c|c|c|}
\hline PIH & 3 & $25 \%$ \\
\hline Anaemia & 6 & $50 \%$ \\
\hline Twin Pregnancy & 3 & $25 \%$ \\
\hline UTI & 0 & $0 \%$ \\
\hline Idiopathic & 0 & $0 \%$ \\
\hline
\end{tabular}

Table 5. Maternal Risk Factors in ELBW Babies Delivered

\section{DISCUSSION}

Preterm delivery is defined as delivery before 37 weeks gestation or before 259 days according to WHO.(1) Preterm deliveries of babies weighing less than 1500 gms (VLBW) and particularly less than 1000 gms (ELBW) are of major concern because of maximum perinatal morbidity and mortality found in this group.

Table no - 1 Shows the distribution of babies delivered on the basis of birth weight, which shows that maximum no of babies delivered (48) were of VLBW categories of birth weight ranging from 1251-1500 gms followed by (21) birth weight ranging from 1001-1250 gms and the minimum no of babies delivered (6)were of birth weight ranging from $<800$ gms.

Table no -2 Shows the distribution of babies delivered on the basis of gestational period, which shows that maximum no of babies delivered (47) were of 33-34 weeks gestational period followed by (21) gestational period were of 31-32 weeks, then (10) babies delivered in gestational period ranging from 29-30 weeks, and the minimum no of babies delivered (6) were of gestational period of $<28$ weeks.

Table no- 3 Shows the maternal antenatal profile associated with the delivery of VLBW and ELBW babies which shows that anaemia in 32 cases (38.09\%) is the most common cause of delivery of VLBW and ELBW babies, followed by PIH associated in 25 cases $(29.76 \%)$ then multiple pregnancy in 12 cases (14.28\%) and idiopathic causes in 11 cases in which no predisposing factors were identified as some of cases were of unbooked category and in least common (4) cases (4.76\%) UTI is identified as predisposing factor for VLBW and ELBW babies delivered. Thus, Anaemia during pregnancy was found to be the most common association (38.09\%) in preterm labour in this study, in another similar study by Roy et al(2) in AIIMS new Delhi found that anaemia was present in $32.6 \%$ cases of 
VLBW and ELBW babies delivered which can correlate with this study.

In another study done by Sehgal et al(3) found that $65 \%$ of patient of preterm labour had anaemia which can be comparable with this study.

Sheikh et al(4) in study found that majority of mothers of VLBW babies had adverse risk factors in which anaemia and PIH are the commonest risk factors associated, which can be comparable with this study.

In our study it was found that PIH was the second most common association with the deliveries of VLBW and ELBW babies which can be correlated with the study done by Sehgal et al(3) found that PIH is one of the common associations with the deliveries of VLBW and ELBW babies.

Similar to other studies, $(5,6)$ we found multiple pregnancy were other common associations with preterm labour which can be correlated with the studies done by Rogowsk et al(7) in which found that multiple pregnancy was associated with the deliveries of VLBW and ELBW babies.

Table no- 4 shows the maternal antenatal profile associated with the delivery of VLBW babies which shows that anaemia in 26 cases $(36.11 \%)$ is the most common cause of delivery of VLBW babies, followed by PIH associated in 22 cases $(30.55 \%)$ then multiple pregnancy in 9 cases $(12.5 \%)$ and idiopathic causes in 11 cases in which no predisposing factors were identified as some of cases were of unbooked category and in least common (4) cases (5.55\%) UTI is identified as predisposing factor for VLBW babies delivered. Thus, Anaemia during pregnancy was found to be the most common association $(36.11 \%)$ in preterm labour in this study

Table no- 5 shows the maternal antenatal profile associated with the delivery of ELBW babies which shows that anaemia in 6 cases $(50 \%)$ is the most common cause of delivery of ELBW babies, followed by PIH associated in 3 cases $(25 \%)$ then multiple pregnancy in 3 cases $(25 \%)$. Thus, Anaemia during pregnancy was found to be the most common association (50\%) in ELBW babies delivered in this study.

\section{CONCLUSIONS}

VLBW \& ELBW babies are always a challenge for a neonatologist with regard to good neurodevelopmental outcome. We found that anaemia, pregnancy induced hypertension, twin pregnancy, and UTI with pyelonephritis were common associations with preterm delivery. Some of these risk factors may be remediable if adequate antenatal care is provided, and timely medical intervention is done.

\section{REFERENCES}

[1] World health organization. The prevention of perinatal mortality and morbidity, Geneva, Switzerland: WHO technical report series report 1970: p. 457.

[2] Roy KK, Baruah J, Kumar S, et al. Maternal antenatal profile and immediate neonatal outcome in VLBW and ELBW babies. Indian J Pediatr 2006;73(8):669-73.

[3] Sehgal A, Telang S, Passah SM, et al. Maternal and neonatal profile and immediate outcome in ELBW babies. Indian Pediatric 2003;40(10):991-5.

[4] Shaikh SM, Mujawar RU. Impacts of transcatheter device closure of atrial septal defect on right ventricular remodelling. International Medical Journal 2017;4(5):659-62.

[5] American College of Obstetricians and Gynecologists. ACOG Practice Bulletin. Assessment of risk factors for preterm birth. Clinical management guidelines for obstetrician-gynecologists. Number 31, October 2001. Obstet Gynaecol 2001;98(4):709-16.

[6] Kramer MS. Determinants of low birth weight methodological assessment and meta-analysis. Bull WHO 1987;65(5):663-737.

[7] Rogowsk JA, Horbar JD, Staiger DO, et al. Indirect vs direct hospital quality indicators for very low birth weight infants. JAMA 2004;291(2);202-9. 